\title{
Seeing and Believing: Metaphor, Image, and Force
}

\section{Citation}

Moran, Richard. 1989. Seeing and believing: metaphor, image, and force. Critical Inquiry 16, no. 1: $87-112$.

\section{Published Version}

http://dx.doi.org/10.1086/448527

\section{Permanent link}

http://nrs.harvard.edu/urn-3:HUL.InstRepos:3157886

\section{Terms of Use}

This article was downloaded from Harvard University's DASH repository, and is made available under the terms and conditions applicable to Other Posted Material, as set forth at http:// nrs.harvard.edu/urn-3:HUL.InstRepos:dash.current.terms-of-use\#LAA

\section{Share Your Story}

The Harvard community has made this article openly available.

Please share how this access benefits you. Submit a story.

\section{Accessibility}




\section{| CHICAgo JOURNALS}

Seeing and Believing: Metaphor, Image, and Force

Author(s): Richard Moran

Source: Critical Inquiry, Vol. 16, No. 1 (Autumn, 1989), pp. 87-112

Published by: The University of Chicago Press

Stable URL: http://www.jstor.org/stable/1343627

Accessed: 06/07/2009 16:56

Your use of the JSTOR archive indicates your acceptance of JSTOR's Terms and Conditions of Use, available at http://www.jstor.org/page/info/about/policies/terms.jsp. JSTOR's Terms and Conditions of Use provides, in part, that unless you have obtained prior permission, you may not download an entire issue of a journal or multiple copies of articles, and you may use content in the JSTOR archive only for your personal, non-commercial use.

Please contact the publisher regarding any further use of this work. Publisher contact information may be obtained at http://www.jstor.org/action/showPublisher?publisherCode=ucpress.

Each copy of any part of a JSTOR transmission must contain the same copyright notice that appears on the screen or printed page of such transmission.

JSTOR is a not-for-profit organization founded in 1995 to build trusted digital archives for scholarship. We work with the scholarly community to preserve their work and the materials they rely upon, and to build a common research platform that promotes the discovery and use of these resources. For more information about JSTOR, please contact support@ jstor.org.

The University of Chicago Press is collaborating with JSTOR to digitize, preserve and extend access to Critical Inquiry. 


\section{Seeing and Believing: Metaphor, Image, and Force}

\section{Richard Moran}

One way in which the characteristic gestures of philosophy and criticism differ from each other lies in their involvements with disillusionment, with the undoing of our naivete, especially regarding what we take ourselves to know about the meaning of what we say. Philosophy will often find less than we thought was there, perhaps nothing at all, in what we say about the "external" world, or in our judgments of value, or in our ordinary psychological talk. The work of criticism, on the other hand, frequently disillusions by finding disturbingly more in what is said than we precritically thought was there. In our relation to the meaningfulness of what we say, there is a disillusionment of plentitude as well as of emptiness. And no doubt what is "less" for one discipline may be "more" of what someone else is looking for.

In recent years, metaphor has attracted more than its share of both philosophical and critical attention, including philosophical denials of the obvious, as well as critical challenges to the obviousness of the ways we talk about metaphor. In this paper I discuss a problem of each sort and suggest a complex of relations between them. The particular denial of the obvious that I'm interested in is the claim recently made by Donald Davidson that "a metaphor doesn't say anything beyond its literal meaning (nor does its maker say anything, in using the metaphor, beyond the literal)," nor is it even correct to speak of metaphor as a form of communication. ${ }^{1}$ There's disillusionment with a

1. Donald Davidson, "What Metaphors Mean," in On Metaphor, ed. Sheldon Sacks (Chicago, 1979), p. 30; hereafter abbreviated "WMM." Davidson's view has 
vengeance; and even if not strictly believable, it is still not without its therapeutic value, as we shall see.

Rather than being deflationary, the critical or interpretive question I want to take up means to make a problem of two common ways of talking about metaphor. Both philosophers and literary critics call metaphor a figurative use of language. So perhaps it should not be surprising that discussions of metaphor so often refer to its imagistic or picturing dimension as being central to a metaphor's power. In a recent book on conceptions of the differences between images and texts, $\mathrm{W}$. J. T. Mitchell mentions the problem of the position of metaphor within this difference:

Literal language is generally understood (by literary critics) as straight, unadorned, unpicturesque expression, free of verbal images and figures of speech. Figurative language, on the other hand, is what we ordinarily mean when we talk about verbal imagery. [Here he cites the second entry for "verbal imagery" in The Princeton Encyclopedia of Poetry and Poetics.] The phrase, "verbal imagery," in other words, seems to be a metaphor for metaphor itself! ${ }^{2}$

And even if other tropes are often called figures, it is through their association with metaphor that they get this name. Among tropes, it is metaphor that is continually and insistently thought of as providing a kind of picture, such as a verbal icon, or a physiognomy of discourse. The reasons for this are anything but clear, for the association persists long after images have lost the place they once had in accounting for the rest of language and thought. The second part of the interpretive problem concerns the equally venerable and no less problematic association of metaphor with force and compelling power. What is the nature of the "force" of metaphor, and what is it supposed to compel? In contrast to nonfigurative language, it's often difficult to distinguish

found supporters among both philosophers and literary theorists. It is, for example, important to the early argument of Richard Rorty's recent book. See his Contingency, Irony, and Solidarity (Cambridge, 1989), p. 18.

2. W. J. T. Mitchell, Iconology: Image, Text, Ideology (Chicago, 1986), p. 21. Although the relation between image and metaphor is not pursued further in this work, Mitchell usefully goes on here to distinguish the sense of figurative language as picturelike from the picturing dimension often claimed for nonfigurative language, for example, the picturing relation between a proposition and the state of affairs that it depicts, as presented in Ludwig Wittgenstein's Tractatus Logico-Philosophicus.

Richard Moran is an assistant professor of philosophy at Princeton University. He is currently working on a book on subjectivity and contemporary concepts of personhood. 
what is meant by the "force" and the "meaning" of metaphor, especially when, in pursuit of clarification about meaning, we are referred to something imagistic. Meaning, image, and force can form a tight circle here, each concept leaning upon the others. Expanding this circle a bit will be helped by taking Davidson's denial of figurative meaning seriously, even if not, in the end, taking it quite literally.

\section{Image and Force}

The association of metaphor with images has several sources, many of which are familiar enough to require only brief mention here. ${ }^{3}$ The metaphorical relation between two things is typically taken to be based on some unobvious resemblance between them, or to be actually productive of such a resemblance. ${ }^{4}$ Sometimes metaphor is regarded as itself a kind of composite picture, the result of two images being fused together. The understanding of a metaphor is taken to involve seeing one thing as another, and discussions of metaphor will often allude to Ludwig Wittgenstein's notion of "seeing an aspect."

3. The association of metaphor with images or pictures has a long history in philosophical theorizing on the subject. Aristotle speaks of metaphor as putting something before the eyes of the audience, or "making your hearers see things" (Rhetoric, 3.1411 b22-29, trans. W. Rhys Roberts, vol. 11 of The Works of Aristotle, ed. W. D. Ross [Oxford, 1924]). In his Aesthetics, G. W. F. Hegel relates metaphor and the image [Bild], that is, the verbal image. See Aesthetics: Lectures on Fine Art, trans. T. M. Knox (Oxford, 1975), pp. 404-10. This is part of a still-popular tradition of conceiving of metaphor as a sensuous or concrete representation for something that is nonsensuous or abstract. Belonging to this tradition as well is Friedrich Nietzsche's comparison of truths and their concepts with "metaphors which are worn out and without sensuous power [sinnlich kraftlos]; coins which have lost their pictures [Bild]." See his "Über Wahrheit und Lüge im aussermoralischen Sinn," Werke in Drei Bänden, ed. Karl Schlechta (Munich, 1966), 3:309-22, for this and further remarks on metaphor and pictures. An extract of this is translated and published as "On Truth and Lie in an Extra-Moral Sense," The Portable Nietzsche, trans. and ed. Walter Kaufmann (New York, 1954), pp. 42-47. In his theory of signs, C. S. Peirce classifies metaphor with the icon, which is his category of signs, such as images, which are based on resemblance between the sign and the thing signified. See "Logic as Semiotic: The Theory of Signs," Philosophical Writings of Peirce, ed. Justus Buchler (New York, 1955), p. 105. The association of force and image, the greater force of images relative to words, has its own history too, which I won't be able to explore here. Roland Barthes alludes to it in distinguishing between the form of the sign and its particular substance (for example, pictorial or written): "This substance is not unimportant: pictures, to be sure, are more imperative than writing, they impose meaning at one stroke, without analysing or diluting it" (Barthes, Mythologies, trans. Annette Lavers [New York, 1972], p. 110). The idea of the greater "imperativity" of pictures over that of words deserves a separate study itself.

4. See Max Black, "Metaphor," Models and Metaphors: Studies in Language and Philosophy (Ithaca, N. Y., 1962), p. 37, and Nelson Goodman, Languages of Art: An Approach to a Theory of Symbols (Indianapolis, 1968), p. 78. 
Among recent writers, Paul Ricoeur has insisted on a "constitutive" role for images (and imagination) in any account of metaphor, whether a psychological account or one that concentrates on the semantic content of the metaphorical assertion. By way of introducing this claim, he says:

The very expression "figure of speech" implies that in metaphor, as in the other tropes or turns, discourse assumes the nature of a body by displaying forms and traits which usually characterize the human face, man's "figure"; it is as though the tropes gave to discourse a quasi-bodily externalization. By providing a kind of figurability to the message, the tropes make discourse appear.

And he cites Tzvetan Todorov as defining "figure" as "the visibility of discourse." We can see that already a certain ambiguity has emerged in the allusions to image and vision. For at first we were concerned with a kind of imagistic relation of resemblance between two things; for example, a person and a wet blanket. And Ricoeur is concerned with this as well in the article cited. In the passage quoted, however, what is said to appear and is likened to a human face is the discourse itself, the utterance or the words.

One motivation for insisting on seeing or on some experiential aspect to understanding metaphor is a sense of the inadequacy, or worse, of the pat paraphrases that are so often proposed in theories that take metaphor to be an indirect statement of resemblance. To call someone a tail-wagging lapdog of privilege is not simply to make an assertion of his enthusiastic submissiveness. Even a pat metaphor deserves better than this, and such an analysis is not essentially improved by tacking on an open-ended list of further dog-predicates that may possibly be part of the metaphor's meaning. Hence it becomes attractive at this point to insist that the comprehension of the metaphor involves seeing this person as a lapdog, and in some detail, experiencing his dogginess. This is what a successful metaphor pulls off, and this image-making quality is what lies behind both the force and the unparaphrasability of poetic metaphor.

Talk about the force or compelling power of metaphor is often bound up with reference to its imagistic capacity. Part of the dangerous power of a strong metaphor is its control over one's thinking at a level beneath that of deliberation or volition. In the mind of the hearer an image is produced that is not chosen or willed. The metaphorical assertion brings one to see something familiar through this

5. Paul Ricoeur, "The Metaphorical Process as Cognition, Imagination, and Feeling," in On Metaphor, p. 142. There is also some discussion of the role of images, the iconic, and "seeing as" in his book, The Rule of Metaphor: Multi-disciplinary Studies of the Creation of Meaning in Language, trans. Robert Czerny (Toronto, 1977), pp. 187-215. 
image, framed by it, and this "seeing" persists concurrently with one's original sense of the dissimilarity of the two things here being brought together. And the full appreciative comprehension of a metaphor can make any subsequent denial of the point it makes seem feeble or disingenuous, in much the same way that appreciative understanding of a joke can overpower any subsequent refusal of the point it makes. If someone is described as having all the charm of a damp kitchen sponge, it's no good simply to deny it, after he or she has registered an appreciation of the phrase. In an article comparing metaphor and jokes, and the ways speaker and hearer are "drawn closer to one another," Ted Cohen says, "When the device is a hostile metaphor or a cruel joke requiring much background and effort to understand, it is all the more painful because the victim has been made a complicitor in his own demise."6 But what is special about this speech situation is that no one, I think, would speak of an ordinary literal insult in this way. Understanding here does not bring any special complicity with it, not with the assertion nor with its intent. "Getting the point" here does not interfere with denying or repulsing it. Nonetheless, Cohen is surely on to something. Metaphor does appear to have a force that goes beyond agreement with what it asserts. Wayne Booth is responding to the same sense in the following passage:

Part of what is communicated does not depend on the metaphor succeeding in the sense of winning or even in the sense of being thought good. The speaker has performed a task by yoking what the hearer had not yoked before, and the hearer simply cannot resist joining him; they thus perform an identical dance step, and the metaphor accomplishes at least part of its work even if the hearer then draws back and says, "I shouldn't have allowed that!"'

What is the compulsion here, what is it that the hearer cannot resist joining in, and what is the nature of his or her complicity? (Later, Booth characterizes understanding a metaphor as deciding "either to be shaped in the shape his metaphor requires or to resist.") ${ }^{8}$ It is almost as if the imagistic "seeing" of metaphor comprehension really involved one's seeing things that way, that is, believing them to be that way, which would give us no way to distinguish between understanding a metaphorical assertion and believing it. A powerful trope indeed.

6. Ted Cohen, "Metaphor and the Cultivation of Intimacy," in On Metaphor, p.

7. Wayne Booth, "Metaphor as Rhetoric: The Problem of Evaluation," in On Metaphor, p. 52.

8. Ibid., p. 63. 
This alone should make us suspicious of the idea of force in metaphor. For there is no category of utterances that necessarily produce, when understood, agreement or belief in what they assert, any more than an utterance can automatically produce understanding of its meaning. But if neither in belief nor in meaning, then where are we to locate the power of metaphor so often praised and blamed? "Force" is a notoriously equivocal word, especially when applied to discourse; still, it seems clear enough that the metaphorical force in question can be neither that of assent to nor understanding of the assertion, nor J. L. Austin's "illocutionary force" (the metaphorical utterance is not itself the accomplishment of any social act, aside from the bare illocution of calling or saying), nor the cogent force of a convincing argument. This is not to say that any or all of these types of force can't apply to this or that metaphorical utterance. Performatives, for instance, can themselves be couched in metaphor. But the power we hear about in connection with metaphor, which the "hearer simply cannot resist," is supposed to be something peculiar to metaphor, and perhaps other figurative language. It ought, then, to be related in some way to the content of a metaphorical assertion, to what it says, and should not turn out to be something that applies equally well to any and every other use of language.

A similar point applies to the association of metaphor with images. That is, there ought to be some special reason for the meaning of metaphor to be couched in imagistic terms, a reason that doesn't apply as well or as poorly to other speech. There is no one today, I think, who would identify understanding the meaning of a word with the having of a mental image (or "idea"), though this and related ideas did dominate thinking about language for some time. Is metaphor, then, taken to be a case of language-use for which such a prototheory is actually true, where, in Wittgenstein's chiding phrase, "uttering a word is like striking a note on the keyboard of the imagination"? "There's no need to deny that uttering a metaphor may give rise to a play of images in the mind of the hearer; however, there is no reason to think that it must always be so, or that this is what constitutes the full understanding of a metaphor. Nor is it only strictly visual images that are inessential to the figurative. For example, there's no morsel for the mind's eye, ear, nose, or throat in Theseus's figurative saying that the poet's pen "gives to aery nothing / A local habitation and a name."

There are still deeper problems with thinking of the meaning of metaphor in terms of images, problems internal to the nature of an image. For a metaphor is semantically articulate in a way that a pic-

9. Wittgenstein, Philosophical Investigations, trans., G. E. M. Anscombe (Oxford and New York, 1953), sect. 6. 
ture is not; it has parts that perform different functions. In many metaphors both terms interact with each other, altering our experience of both items of the comparison. There are many other metaphors, however, that work in one direction only, and are not reversible without change of meaning. For example, when we read in Wordsworth "Thy soul was like a Star, and dwelt apart," our ar; ;rehension of both souls and stars is affected, each taking on aspects of the other. But, on the other hand, the floral and culinary stock in trade of erotic metaphor is rarely reversible. If we are enjoined to imagine a garden in her face or lips like cherries, we may be sure we are not to read against the grain in the direction of a face in the garden or cherries like lips. ${ }^{10}$ This is why so many analyses of metaphor contain at least two terms for its functioning parts (I. A. Richards's "tenor" and "vehicle," Max Black's "frame" and "focus," and so on). An image, a real image, can't tell us what is being imagined as what; and yet, there is a difference between seeing oak leaves as hands and seeing hands as oak leaves. ${ }^{11}$ An image could provide you with nothing more than a kind of composite picture in which you could discern features of each of them. This, I believe, shows what is misguided about any theory of metaphor as based on the psychoanalytic mechanism of condensation, which is said to function like a composite photograph. ${ }^{12}$ It also forces us to rethink the role of resemblance in metaphor (and in simile, too, for that matter). For resemblance and similarity are both symmetrical relations: if $A$ resembles $B$, then $B$ resembles $A$. Hence, if metaphor were some kind of assertion of resemblance, we should be able to reverse any of the parts without loss or change of meaning.

10. William Gass has some remarks on this in his On Being Blue: A Philosophical Inquiry (Boston, 1975), pp. 39-40. Black notes the irreversibility of certain similes in "How Metaphors Work: A Reply to Donald Davidson," in On Metaphor, p. 186 n.23.

11. This difference in meaning is not dependent on the context being one of predication, but it will obtain even in the case of "mere" verbal juxtaposition. Even the imagists didn't get to images: the petals on a wet black bough are not themselves seen as faces in a crowd. The criticism of the appeal to images was one of I. A. Richards's original motivations for introducing the terminology of "tenor" and "vehicle." See his Philosophy of Rhetoric (Oxford, 1936), pp. 98-99.

12. Freud frequently compares the mechanism of condensation in dream-work to the composite photographs of faces produced by Francis Galton. See The Interpretation of Dreams, The Standard Edition of the Complete Psychological Works of Sigmund Freud, trans. and ed. James Strachey, 24 vols. (London, 1953-74), 4:139, 293, and 5:494.

This is also one thing that discourages thinking of caricatures and the like as "visual metaphors" (see Goodman, Languages of Art, pp. 84, 89). Even though not all metaphors are "one-way," the possibility of drawing the distinction in direction seems internal to metaphor but not to pictures. Context, of course, will normally leave us in no doubt as to whether some picture is that of Churchill-as-bulldog or bulldog-asChurchill. 
Finally, the appeal to images gives us an especially bad model for accounting for the endlessness of the paraphrase or elaboration of a living metaphor. This endlessness is a familiar fact about poetic metaphor, and may even itself contribute to the association with images, via the notion that it is a picture that is worth a thousand interpretive words in such a case. But what kind of picture would we get if we tried to visualize the various parts of the manifold of paraphrase and pack them into a single image? Stanley Cavell provides a sample gloss on the phrase "Juliet is the sun," in the course of which he says that "Romeo means that Juliet is the warmth of his world; that his day begins with her; that only in her nourishment can he grow. And his declaration suggests that the moon, which other lovers use as emblems of their love, is merely her reflected light, and dead in comparison; and so on." 18 Of the items mentioned here, even the ones that do relate to something visual can't all be combined into a single image. The further we go on with the gloss, including the dawn, growth and nourishment, the moon, the planets, the changing seasons, and so on, the more absurd becomes the attempt to see all this as contained in something identifiable as an image. And yet part of the original attraction of the "image" idea was the unifying or organizing function claimed for an image; yet, in fact, you just don't get anything like a picture by putting all these things together. And a concessionary appeal to several images at this point fails to explain or justify any recourse to images in the first place.

\section{Davidson's Choice}

Much of what I've said about images so far has been predicated on the assumption that metaphors do mean something, or rather, that speakers mean things by them, use them to say something or other. However, if this is wrong then my objections based on considerations of paraphrase, on change of meaning when the terms are reversed, and so on will not apply. If one denies that the metaphor-speaker is involved in saying anything distinct from what his or her words literally mean, then perhaps the way is open to seeing metaphor as functioning like a picture after all, with "force" applying to it only as it may to a picture, which doesn't literally say anything. And in making just this denial, Davidson does make passing comparison of metaphors and pictures:

13. Stanley Cavell, "Aesthetic Problems of Modern Philosophy," Must We Mean What We Say? A Book of Essays (1969; Cambridge, 1976), pp. 78-79. 
What I deny is that metaphor does its work by having a special meaning, a specific cognitive content. . . . - to suppose it can be effective only by conveying a coded message is like thinking a joke or a dream makes some statement which a clever interpreter can restate in plain prose. Joke or dream or metaphor can, like a picture or a bump on the head, make us appreciate some factbut not by standing for, or expressing, the fact. ["WMM," p. 44] $]^{14}$

The main focus of Davidson's attack is the idea of metaphor-meaning, as mentioned above. The literal meaning of the words or phrase is all the meaning there is in such a case. Yet he warns against taking this to be merely a terminological issue, "an insistence on restraint in using the word 'meaning"':

This would be wrong. The central error about metaphor is most easily attacked when it takes the form of a theory of metaphorical meaning, but behind that theory, and statable independently, is the thesis that associated with a metaphor is a cognitive content that its author wishes to convey and that the interpreter must grasp if he is to get the message. ["WMM," p. 44]

Hence, the use of metaphor has certain effects on the hearer, but these do not constitute the meaning of the metaphor; and even if among these effects is that the hearer comes to notice or realize something, this is not something the speaker has said or intended to communicate.

The sense of "meaning" that Davidson has in mind is strictly that of meaning-in-a-language, and not what is sometimes distinguished from this as "speaker-meaning." This is somewhat disappointing both because writers who refer to metaphor-meaning have not claimed that a single metaphorical utterance somehow permanently alters the dictionary-meaning of a word, ${ }^{15}$ and also because the distinction between word-meaning and speaker-meaning forms the basis of at least one influential account of metaphor. ${ }^{16}$ And along with an implicit restriction on the word "meaning," Davidson assumes a sense of meta-

14. See "WMM," p. 45 for more on pictures. Rorty (Contingency, Irony, and Solidarity, p. 18) also mentions pictures in his sketch of Davidson's account. I do not mean to suggest that the vindication of any "imagistic" account of metaphor is itself a motivation for what either of them say.

15. See Black, "How Metaphors Work," p. 187.

16. See John R. Searle, "Metaphor," Expression and Meaning: Studies in the Theory of Speech Acts (Cambridge, 1979), pp. 76-116. It would also be useful to know whether Davidson would deny that Gricean implicature is a way of communicating something distinct from what one's words literally mean. H. P. Grice briefly discusses metaphor in 
phor itself that is somewhat narrower than that of other writers on the subject. Although this restriction is partially buried in his essay, it comes out in some remarks he makes at the beginning, as well as in his treatment of the difference between the living and the dead among metaphors.

Early on Davidson says, somewhat surprisingly, "A metaphor implies a kind and degree of artistic success; there are no unsuccessful metaphors, just as there are no unfunny jokes. There are tasteless metaphors, but these are turns that nevertheless have brought something off, even if it were not worth bringing off or could have been brought off better" ("WMM," p. 29). I think he is on firmer ground in the case of metaphor than with jokes. It's hard to believe that anyone who has dwelt in an academic environment for as long as Davidson has would think that he had never encountered an unfunny joke. (Well, perhaps he's only joking here. But what if we decide that he is?) It's true that we do seem to lack terms of criticism for metaphors that apply prior to their succeeding in bringing us to see something in a certain way. Prior to this success we may either irrelevantly criticize the expression as wildly false, or simply confess that we do not understand it. But if some such success is to be definitional of metaphor, we must ask just what it is that has been "brought off" here. This should remind us of Booth's remark that "part of what is communicated does not depend on the metaphor succeeding in the sense of winning or even in the sense of being thought good. The speaker has performed a task by yoking what the hearer had not yoked before, and the hearer simply cannot resist joining him." This "yoking" of two ideas, or the framing of one in terms of the other, is, I think, what Davidson has in mind when he speaks of something being "brought off." Part of the difference between Davidson and Booth on this point is that Booth allows himself to speak of "what is communicated" in this regard, which Davidson, of course, will not do. Also, Booth does not explicitly make success at such framing true by definition of anything we can call a metaphor. Yet this again is not without its motivation. For if no ideas have been linked together, if nothing has been seen in terms of something else, then we just have a statement inexplicable in its gross falsity or in its banal irrelevant truth. So there are no unsuccessful metaphors, but what they succeed at is not the assertion or communication of anything (for example, a statement of resemblance). Their success is at the level of effects, what they get us to associate, or notice, or attend to.

Accordingly, this definition of metaphor in terms of effects leads Davidson to discount, as proposed examples of metaphor, turns of

this connection in his "Logic and Conversation," in Speech Acts, vol. 3 of Syntax and Semantics, ed. Peter Cole and Jerry L. Morgan (New York, 1975), p. 53. 
speech that don't produce such effects. A dead metaphor, such as the "mouth" of a river or a bottle, no longer draws attention to itself, nor does it force attention to any covert likeness between things. What has happened, according to Davidson, is that the field of application of the original term has been expanded to include bottles and rivers, as now literally having mouths. However:

When "mouth" applied only metaphorically to bottles, the application made the hearer notice a likeness between animal and bottle openings. (Consider Homer's reference to wounds as mouths.) Once one has the present use of the word, with literal application to bottles, there is nothing left to notice. There is no similarity to seek because it consists simply in being referred to by the same word. ["WMM," p. 35]

And there is no survival in this death of anything to be called the meaning of the original live metaphor.

So Davidson makes successful achievement of the effects of framing or yoking together a requirement of anything to be called a metaphor. And this requirement operates from two different directions. There are no unsuccessful metaphors, in the sense of metaphors that fail to bring off such effects. And there are no dead metaphors, that is, metaphors that once had such effects and now no longer do. For a dead metaphor, such as "river mouth," is not a metaphor at all, but a (relatively) new literal application of the term "mouth."

Naturally this raises a problem for describing the life cycle of a metaphor. We will have to say that before the birth of the metaphor, it was categorically false, or meant nothing, to speak of the mouth of a river. And then after the metaphor's death, the literal meaning or application of the word "mouth" has been changed to include parts of rivers. Now where did this new meaning come from? The natural assumption is that it is part of what was meant when the metaphor was alive, that it survived the metaphor's death and its loss of imagistic force. Davidson cannot say this since, for him, the live metaphor had no meaning distinct from the literal falsehood carried by the phrase prior to the metaphor's existence. All that was distinctive about the phrase during its life as a metaphor was on the level of effects of vividness and force, and now at its death it has lost these. And yet somehow what remains is a phrase with a posthumous literal meaning different from its original literal one. ${ }^{17}$

17. Related objections to Davidson's account have been made by Goodman ("Metaphor as Moonlighting," in On Metaphor, pp. 175-80), and by David Novitz ("Metaphor, Derrida, and Davidson," Journal of Aesthetics and Art Criticism 44 [Winter 1985]: 101-14). I will not be canvassing all of the merits and problems in Davidson's account. 
The restriction of examples of true metaphor to utterances that succeed at the framing-effect of live metaphor is an option that is also implicitly taken by other writers on the subject. Indeed, there is something of an unacknowledged division in discussions of metaphor between those who believe that only a live metaphor is truly a metaphor, and those who downplay the difference between the living and the dead, taking what is important and distinctive about metaphor to be independent of this difference. Writers who fix on live metaphor will typically also emphasize imagery and force (or various nonassertoric "effects") in their accounts of what is distinctive about metaphor. This is a rough characterization, but in varying degrees it applies to Davidson, Ricoeur, C. S. Peirce, and aspects of the work of Booth and Cohen. On the other hand, those who downplay the difference between live and dead will typically emphasize relations between metaphor and concept-formation, and construe metaphor-meaning more straightforwardly as a kind of assertion (of resemblance, or of identity, or ....). Again roughly, and with varying aptness, this applies to Friedrich Nietzsche, Nelson Goodman, Jacques Derrida, and Paul de Man. ${ }^{18}$ Davidson is distinguished among "live" theorists by his explicitness and extremism, and this has its virtues. If one arrives at the restriction to live metaphor through having previously defined metaphor in terms of its success at "framing-effects," then the problem of accounting for what is said in metaphor is highlighted. For we cannot identify believing what the metaphor says with the effect of framing one thing in terms of another in the mind's eye. Success at this effect

Besides the two papers just mentioned, the interested reader should see Black, "How Metaphors Work."

18. Nietzsche relates the action of metaphor and the process of conceptformation via the notion of "equating what is unequal" [Gleichsetzen des Nichtgleichen] (Nietzsche, "Über Wahrheit und Lüge im aussermoralischen Sinn," p. 313). On this view, a metaphor that has lost its image through long use is what we call a concept, but it is still essentially a metaphor. Following a discussion of Nietzsche, Jacques Derrida asks, "Is rectification henceforth the rectification of a metaphor by a concept? Are not all metaphors, strictly speaking, concepts, and is there any sense in setting metaphor against concept?" (Derrida, "White Mythology: Metaphor in the Text of Philosophy," Margins of Philosophy, trans. Alan Bass [Chicago, 1982], p. 264). Paul de Man presents the same line in the course of a reading of Jean-Jacques Rousseau: "And conceptualization, conceived as an exchange or substitution of properties on the basis of resemblance, corresponds exactly to the classical definition of metaphor as it appears in theories of rhetoric from Aristotle to Roman Jakobson" (de Man, Allegories of Reading: Figural Language in Rousseau, Nietzsche, Rilke, and Proust [New Haven, Conn., 1979], p. 146). In Languages of Art, Goodman explores the aspect of metaphor that involves the reorganization of conceptual realms through the transfer of schemata, a transfer that survives the death of the metaphor. "A frozen metaphor has lost the vigor of youth, but remains a metaphor. Strangely, though, with progressive loss of its virility as a figure of speech, a metaphor becomes not less but more like literal truth" (Goodman, Languages of Art, p. 68). 
is here definitional of metaphor, and even under this restriction not all metaphorical utterances produce belief in what they say. Davidson's solution is to say that there is nothing said by the metaphor beyond what its words mean literally. Without joining him in this conclusion, it's still possible to see how his extreme position performs the service of forcing a certain choice on the theorist of metaphor. Or rather, it enables us to diagnose a certain way of combining a cognitive account with an exclusive concentration on the vivid effects of live metaphor, a combination that produces a confused idea of the "imagistic force" of metaphor.

For if, along with Davidson, one thinks of the (successful) effect of framing one thing in terms of another as being the essence of metaphor, and one combines this with the non-Davidsonian idea that metaphor involves the assertion or communication of some content, one may arrive at the idea of metaphor as somehow carrying within itself forced assent to what it asserts. This is, I think, how Booth ends up speaking of what is irresistible in metaphor in terms of what it communicates. But communication involves a relation between assertion and belief, and is always resistible. And part of what this means is that the notions of communication and of saying require that a distinction can always be drawn between understanding and belief. If one takes the framing or yoking together involved in metaphor to be a nonassertoric effect of the utterance, then one can safely define it in terms of success in bringing off such an effect. But, on the other hand, if this definition is combined with the idea of such framing as an implicit assertion of some kind, then there's no obvious way for us to understand "success" here. The choice, then, is roughly the following. If you take metaphor to be assertive, to be the communication of a content, then you cannot both define metaphor as a case of successful framing and take that framing (or, say, the resemblance thus brought to mind) to be the content of what is communicated. And more roughly still: a theorist who takes some kind of striking effect to be essential to metaphor, who concentrates on live metaphors and their imagistic power, is well advised not to think of metaphor as the assertion of something distinct from the literal. Or at least he or she will have to look somewhere else for that content than in the framingeffect (imagistic or otherwise) that the metaphor succeeds in bringing off.

One further reason should be mentioned in favor of Davidson's idea that what is distinctive about or essential to metaphor is on the level of effects (of what I've called framing and the like), and that the framing-effect cannot be construed as the content of an assertion. Consideration of the example of negative metaphorical statements, such as "no man is an island," shows that the vividness or force of a metaphor cannot be carried by the assertion of resemblance or iden- 
tity. ${ }^{19}$ For it will be seen that such an utterance still succeeds in yoking two things together in the mind of the hearer, even though the corresponding statement of resemblance between the two things is here denied. The denial of a metaphorical statement still retains the effect of framing, of seeing one thing in terms of another. What is retained in such a case can't be the same thing that is asserted in the affirmative metaphor-statement, and can't be the same thing that is a possible object of belief in the affirmative statement. Otherwise the statement and its denial would make the same assertion, express the same belief. It is this sense of the framing-effect as a positive thing that a subsequent denial of the statement is powerless to undo which I believe is responsible for the talk of compulsion and involuntary complicity in discussions of metaphor. Even Davidson speaks of the audience for metaphor being "bullied" into making a certain comparison ("WMM," p. 39). Something like this is surely part of what is meant by the "force" of a good metaphor; but in such cases what is forced, or can't be undone, is not a believing of what is asserted. ${ }^{20}$

On the other hand, it's not at all unlikely that the exclusive importance of belief in such contexts has been somewhat oversold in philosophical thinking on the subject. There are more ways of changing someone's mind than changing his or her beliefs. Although this may be most easily seen in the case of rhetoric, it is quite generally true for both philosophy and literature that much of what they aim at is not on the level of specifically altered beliefs but rather such things as changes in the associations and comparisons one makes, differences in the vivid or "felt" appreciation of something already known, or changes in one's habits of attention and sense of the important and the trifling. And although such changes of mind are something different from the acceptance or rejection of certain beliefs, there is nothing to be gained by assimilating them all to the category of the

19. Cohen has discussed such cases as examples of metaphors, which he calls "twice true," that is, statements that are true both as literal statements and as metaphors. See his "Notes on Metaphor," Journal of Aesthetics and Art Criticism 34 (Spring 1976): 249-59.

20. Even though the framing-effect is itself independent of the assertoric mood, it will naturally very often be exploited by that mood. In such a case the "force" in question can quite directly involve change of belief. Kenneth Burke considers the " "unearned increment" " of associated ideas gained by a political speaker who argues for some measure in terms of the image of the mother rather than in terms of the abstract idea of "security." See his Rhetoric of Motives (Berkeley, 1969), p. 87. We can see at least two rhetorical advantages to such a tactic. It will lend persuasive force to an utterance not only because the speaker can communicate the other associated ideas (of tradition, affection, and so on) without committing himself to them, but also because such ideas are received by the audience more as discoveries about something than as claims made by some (possibly unreliable) person. 
"noncognitive." Appreciation of this will have literary, political, and philosophical consequences for the criticism of metaphor.

\section{Images and the Unmentionable}

The indifference of the force of a good metaphor to the moods of affirmation or denial may also be part of what suggests the comparison with pictures. The framing-effect of a metaphor survives when the statement is denied, subsumed in a hypothetical or a part of a question, or placed in quotation marks. And whether or not we want to say that a picture means anything, it does whatever it is a picture does in a way that has nothing to do with the different grammatical moods. And this is important for the effectiveness of both metaphors and pictures.

There are often advantages, rhetorical and otherwise, in somehow letting a certain thing be known or inferred by your audience, instead of explicitly saying it. A picture can be used to get a point across without incurring the risks and responsibilities of asserting that point. This can disarm criticism of the point being made, while retaining the intended effect of the picture. Likewise, in verbal abuse it is also possible to make one's message clear not only without asserting it, but while explicitly denying or disavowing it. If what is objectionable about some utterance is in what it says or asserts, then the response of denial and counterassertion is appropriate, and such a response is successful to the extent that what $i t$ says is believed instead of the original statement. Yet there are other aspects of an utterance that cannot be countered in this way. Among these are such things as mentioning or bringing up something (without explicitly saying anything about it), or repeating someone else's words in a mocking tone of voice, and making a certain comparison or drawing attention to something without making any particular claim about it. The invidious comparison of one's rival with a hyena can be successfully accomplished even in the context of explicit denial that that is what one is doing, or when one claims to be making no assertion of one's own but merely quoting someone else's words. Here since the damaging effect is not carried by the assertion, it is not well countered by a denial of the assertion.

For example, praeteritio exploits the fact that something decisive gets through to the audience even when the nested assertion is denied, subsumed in a hypothetical, a part of a question, and so on. "If I were to bring up the sordid facts of his private life I could justly be accused of descending into personal attack, therefore I merely. . . ." Praeteritio relies on, and furthers, those aspects of a statement that are indifferent to its grammatical mood, which include mentioning or referring to things, as well as the vividness and force of a good meta- 
phor. Praeteritio will be more memorable and more effective when the nested assertion is a live metaphor; for everything relating to the effect of seeing one thing as framed by another will survive the pretended disavowal. Elaborate metaphorical verbal abuse like this will naturally make the bad faith of the disavowal transparent, for it will reveal the work of the figure, and not the assertion, to have been the point all along.

Pictures share with metaphors the capacity to get a point across in a way that is indifferent to grammatical mood or to the distinction between bringing something up and saying something in particular about it. Grammatical mood and the distinction between assertion and "mere" mention simply don't apply to pictures. In language we can distinguish between reproducing someone's utterance when it is quoted, and reproducing someone's words to make the same assertion oneself. On the other hand, when it comes to reproducing a picture, there doesn't seem to be anything like the distinction between mention and use, and it's not clear that either of the alternatives has any application, or that pictures per se have the notational resources for actual quotation. There is indeed a sense in which one picture may allude to or even contain another one. But such reference or allusion to another picture is not analogous to the distinction between asserting something oneself and quoting the words of someone else's assertion. Verbal quotation abstracts from the context of a particular speech act, whether assertion, question, or command. However we want to characterize what a picture does when it makes us see something in a certain way, or when it comments on something, or suggests a certain comparison, it accomplishes this in a way that is indifferent to the distinction between quotation and assertion.

Because of this, church leaders and others interested in banning certain pictures are sometimes faced with the problem that there is no such thing as "mere" quotation of pictures, that reproducing them for purposes of commentary and censure entails repeating the effects that were the object of censure in the first place. In speech one can reproduce someone else's statement without asserting it oneself, that is, when one just quotes it. So if it is the assertion and the belief it expresses that is objectionable, one can avoid compounding what is wrong by reproducing it in a quotation, a question, or a hypothetical. On the other hand, pictures can't be "merely" quoted since there is no assertoric dimension to abstract from..$^{21}$ (Naturally this doesn't mean there may not be anything to object to, nor that a picture is not

21. See Peirce, "Logic as Semiotic: The Theory of Signs," p. 111: "Icons and indices assert nothing. If an icon could be interpreted by a sentence, that sentence must be in a 'potential mood,' that is, it would merely say, 'Suppose a figure has three sides,' etc." 
both productive of and reflective of particular beliefs.) The anxiety concerning the impossibility of "mere" quotation in pictures may be compared to the anxiety concerning the inadequacy of quotation when verbal obscenities are in question. My grandmother would no more quote someone else's indecent language than she would use it herself. The distinction between use and mention would seem pointless here, since what matters about verbal obscenity is on the level of effects carried by the utterance, and not the particular assertion made by it. Quoting such an obscene statement does not neutralize or disarm it; nor does it neutralize the effect of a strong metaphor. ${ }^{22}$

Praeteritio requires the pretense that the language-game being played is one of assertion and counterassertion (a language-game to which the possibility of quoting rather than asserting is internal), so that the disavowal of a particular claim is supposed to leave one's opponent with no recourse, since there is no (relevant) claim to be countered. Such a pretense becomes laughably transparent when the disavowal involves abusive verbal obscenity. The pretense is only slightly less transparent when the praeteritio is conducted in richly metaphorical language (which is what most verbal obscenity is anyway). In both cases what is crucial to the utterance is not carried by the assertion, yet it is smuggled in under cover of the language-game of assertion. By contrast, there is no corresponding technique for pictorial praeteritio because there is no corresponding pretense of a context of assertion for us to flirt with, a context of assertion which may be cancelled through "mere" quotation. Recently it was reported that Princess Diana was made upset by an ugly puppet caricature of her on television. In the supermarket paper announcing this, the mock compassionate headline "This Cruel Puppet Made Poor Princess Di Cry" was, of course, accompanied by a full-page picture of the offensive puppet in question. Here one couldn't even pretend to claim to be doing something like merely quoting rather than something like asserting. Any objection to the original applies equally to the duplicate. The distinction between assertion and (mere) quotation doesn't obtain here; hence there's no room for pretense involving shifting from one context to the other.

22. Alternatively, one could say that the effective functioning of metaphor is indifferent to the distinction between quotation and assertion because the symbolic workings of metaphor require that the utterance be treated as if it were already within quotation marks. This idea is central to Dan Sperber's account of symbolism in general, both verbal and nonverbal; see his Rethinking Symbolism, trans. Alice L. Morton (Cambridge, 1975), pp. 99-105. One accepts the symbolic utterance before knowing its meaning, as one may know a certain quoted sentence to be a true sentence without knowing what statement it expresses. Taking the utterance in quotes is what opens it to interpretation. 


\section{Recovering Meaning}

These considerations about the functioning of nonassertoric effects offer some support for Davidson's case against thinking of the meaning of a metaphor as the content of an assertion, and are meant to throw some light on the familiar comparison of the workings of metaphor with pictures or images. Nonetheless there are several reasons for thinking that this can't be the whole of the story. For one thing, if the metaphoric utterance makes no assertion at all (other than the literal one), the idea of a denial of it won't make any sense either, except in the unlikely cases where what one means to deny is the literal categorical falsehood carried by the words. For just as what I've called "negative metaphor" is still metaphor, so the denial of a metaphorical statement is normally the denial of the statement taken metaphorically and not literally. But then there must be some metaphorical statement being denied, a statement distinct from the literal one. So even if, as I've said, the denial of a metaphorical statement retains the framing-effect of the original assertion, that does not mean that something has not been denied. It must be possible to deny a statement taken metaphorically; it must also be possible to either understand or misunderstand such a statement, that is, to take it metaphorically but take it in the wrong way.

It doesn't seem possible to describe this sort of familiar case within Davidson's theory, and it's not easy to determine what he would even want to say on this point. For he denies that metaphor is "a form of communication" or "primarily a vehicle for conveying ideas," and he denies that the speaker of metaphor says anything beyond the literal ("WMM," p. 30). But he does not deny that a metaphor has a point ("WMM," p. 30), or that there is such a thing as "understand[ing]" a metaphor ("WMM," p. 31), which involves seeing "what the author of a metaphor wanted us to see" ("WMM," p. 45); and he says that the decision to use a certain metaphor rather than the corresponding simile involves choosing "to get the idea across a different way" ("WMM," p. 39). It's not obvious how such concessions can leave his account with much more than "an insistence on restraint in using the word 'meaning," or can be consistent with his central denial that "associated with a metaphor is a cognitive content that its author wishes to convey and that the interpreter must grasp if he is to get the message" ("WMM," p. 44). ${ }^{23}$ Whatever we want to call it, there is that in the metaphoric utterance which is distinct from the lit-

There are some clear affinities (as well as differences) between what I say about metaphor here and what Sperber says about symbolism, and I have profited from his book.

23. In reprinting this article, Davidson made a few changes and altered this sen- 
eral assertion, which can be understood or misunderstood, and which we interpret in a way that depends, in part, on our beliefs about the speaker's beliefs. That is, in order to understand what the speaker means who tells us that "man is not a man, but a wolf, to those he does not know," we have to rely on what we take him to believe about wolves and what is important about them. And if we are very wrong about this, we will misunderstand what he means to convey (say, if we thought he believed wolves were benign parasites). And we are not in the same way dependent on anyone's beliefs when a bump on the head makes us appreciate the fact that we forgot to duck, which is the reason we don't think of this situation as involving the communication of anything.

The claim that metaphor involves the communication of content is independent of the claim that it involves a change in the meaning of the words. Talk about "meaning" is probably best avoided anyway, since its range is so wide and there's so little agreement about it. The independence of the two claims, however, can be seen by comparing metaphor with irony. Like metaphor, irony operates in a way that is dependent on the standard meanings of the words used, and this dependence is exploited in order to express something distinct from the standard meaning of the assertion. And as far as I know, no one has yet denied that irony or sarcasm involve the intention to convey something distinct from the literal, something that can be missed or misunderstood. Still, at the same time, no one claims that irony or sarcasm involve a change of meaning in the words used. We speak ironically, but we don't speak of ironic uses of words, or of attaching an ironic sense to a word. When someone says ironically of his betrayer that he is "a fine friend," he doesn't mean that he is ironically a fine friend, or that he is one in an ironic sense. And nothing in ironic speech attaches to the individual words in such a way as to eventually enter the dictionary. (In this sense, there are no "dead ironies.") Irony attaches to whole utterances, not individual words. And it manages to communicate something distinct from the literal (when it does) without change in the meanings of the words.

For both ironic and metaphorical utterances, it is the fact that we can either understand or misunderstand them, and that we rely on beliefs about the speaker's beliefs in order to understand, that makes the situation a communicative one. And the possibility of misunderstanding, along with this reliance on beliefs about the speaker, must be part of an account of metaphor if it is to avoid consequences that trivialize metaphor beyond recognition. Davidson mentions this possibility in

tence to be the denial that metaphor has a "definite" cognitive content associated with it (Davidson, Inquiries into Truth and Interpretation [Oxford, 1984], p. 262). But the question of definiteness makes no essential difference to the main point. 
the course of criticizing theories of metaphor that make it out as a compressed or elliptical simile:

They make the hidden meaning of the metaphor all too obvious and accessible. In each case the hidden meaning is to be found simply by looking to the literal meaning of what is usually a painfully trivial simile. This is like that-Tolstoy like an infant, the earth like a floor. It is trivial because everything is like everything, and in endless ways. ["WMM," p. 37]

The endless trivial ways in which one thing can be like another show up just how endless are the ways in which one can go wrong in the interpretation of a metaphor. It may well be true, as Davidson says, that "a metaphor makes us attend to some likeness" ("WMM," p. 31), but it is not true that attending to just any of the infinite aspects of likeness between the two things counts as understanding the metaphor. And we are guided by our beliefs about what the speaker believes about the things in question when we select from this infinity in the process of interpreting the metaphor.

But the point about our selectivity and its dependence on beliefs about the speaker goes deeper than this. This selectivity is not simply an aid to avoiding error in interpretation. Rather, the process of interpretation couldn't even begin without some sense of which are the relevant dimensions of the comparison. For it is not as if we could take all the facts and beliefs about wolves (whatever that would be) and use them as a perspective on all the facts about people's relations to strangers. That wouldn't provide us with so much as a perspective to begin interpreting. The metaphor will not succeed in getting us to see anything as anything without our having some previous understanding of which aspects of a wolf are being used as a perspective on which aspects of human beings. (The fact that they may both have grey hair, or require sleep, is probably not the point.) It is thus arguable that an utterly uninterpreted metaphor, one for which we have no clue which features are irrelevant, does not yet succeed in even "yoking" two things together. That is, we must have some sense of the field of comparison, otherwise "yoking" or "framing" can mean no more than the empty exercise of keeping the two things together in mind: the taste of sugar and the discovery of America.

An account of metaphor that denies that it is a form of communication will thus not only have difficulty saying what understanding or misunderstanding can consist in, it will also encounter problems in saying how the nonassertoric framing-effect takes place. ${ }^{24}$ For, as I

24. For similar reasons, Davidson lacks an account of why all similes are not "painfully trivial” ("WMM," p. 37). 
briefly suggested, the effect of framing one thing in terms of another is itself dependent on a prior understanding of what areas of comparison are relevant, and determination of this relevance is dependent on what we take the speaker to have in mind. This is not to say that the interpretation of metaphor is restricted to an elaboration of what its author is taken to have understood by it. There is more to the interpretation of any utterance than that. And it is especially the case with metaphorical speech that its author too will often expect there to be more in it than he originally thought, and will hope to be surprised by where its explication leads him. Still, the dependence on the speaker is not eliminable in an account of either the interpretation of metaphor or its original framing-effect. A noncognitive theory of metaphor will not be able to account for this dependence on beliefs about the speaker's beliefs, or say what it is that we depend on such beliefs for. Such an account will not be able to say that we depend on those beliefs for the determination of the (nonliteral) content that the speaker meant to communicate.

\section{Metaphoric Thought}

The speaker's beliefs about wolves and men, or tempests and teapots, must also be part of any account of what he is doing in formulating the metaphor in the first place. We need an explanation of his devising just the particular metaphor he does. It's not just a matter of his manufacturing some phrase and seeing what effect it will have when uttered. ${ }^{25}$ In the effort to formulate a metaphorical statement there will often be considerable struggle before one feels one has "got it right," that the right adjustment has been made. If Davidson is correct, however, there can't be anything one is getting right here. But when a metaphor is "right," it is so not only for what it gets one to notice, but also for its adequacy in expressing what one has already noticed. The speaker or writer has certain beliefs about wolves and about human behavior, and he is thinking about one in terms of the other. To get to this point, however, he had to have certain beliefs

25. In his reply to Davidson, Black says that if Davidson is understood as offering a kind of speech-act theory of metaphor then he cannot account for the use of metaphor by a soliloquizing thinker, for whatever resemblance metaphor is supposed to draw attention to will necessarily have already occurred to the thinker (Black, "How Metaphors Work," pp. 188-89). I think Davidson could reply that the solitary thinker can still benefit from the nonassertoric effects of a good metaphor, and that soliloquy is no more mysterious here than when one asks oneself a question and answers it. The point I'm making here, on the other hand, separates the issue of the cognitivity of metaphor from that of its role in assertion and communication, and locates the problem in the composition of metaphor, and not in soliloquy. 
about human interaction that suggested the comparison with wolves in the first place and that determine which aspects of that relation the comparison is meant to illuminate. The effort to formulate a particular metaphor is initially guided by and in the service of these beliefs. The right phrase, the right comparison, will both sharpen and organize these thoughts as well as lead the composer to notice new things, leading to new thoughts. Without referring to those (perhaps vague or indeterminate) initiating beliefs, we cannot account for why that particular metaphor was devised, why that comparison seemed apt or not. And once such beliefs are included in the account of the composition of the metaphor, there seems little motivation left for denying that these beliefs, indeterminate or not, are at least part of what the speaker means to communicate.

I have used terms like "framing-effect" and "perspective" to speak of the dimension of metaphor that is distinct from what is asserted either literally or metaphorically. As the word "perspective" suggests, this aspect of metaphor is not itself an object of belief or denial. It is the effect of a poetic metaphor that survives denial and is indifferent to quotation or grammatical mood. It is concentration on this dimension that suggests the comparison of metaphor with figures or pictures. Success in bringing off this effect, in bringing someone to adopt this perspective momentarily, is independent of belief in any particular assertion. Hence confusing the framing-effect with an assertion of some kind can lead to misinterpreting the force of metaphor as a kind of forced assent to what it says, as if it were the assertion itself which was found to be irresistible.

Speaking of the adoption of a perspective is useful precisely because it is neutral with respect to belief and assertion. But if this were the only dimension of metaphor, then we couldn't explain, among other things, what denying the statement comes to. For the denial is not the refusal to adopt the perspective, any more than the original statement is simply the invitation to take up that perspective. The speaker does not say, "Imagine Juliet as the sun"; rather he makes a statement about Juliet. She is the object of his thinking, and various beliefs of his about her are necessary to account for his original adoption of this perspective. And someone who denies that statement will be sharing that perspective for the moment, but disagreeing with some of what Romeo believes.

To sum up, then: there are two dimensions of metaphor, the dimension of effects, which I've referred to in terms of framing or the adoption of a perspective, and the dimension of the beliefs that prompt the comparison in the first place, and which are necessary for the framing-effect to be something other than mere juxtaposition. The belief-dimension must have a place in the account of both the speaker's composition of the metaphor and the audience's understand- 
ing of it. In the case of the composer, he does not simply come up with an expression, accept its adequacy, and then figure out what it is adequate to and in just what ways. Rather he will have, for example, various beliefs about one person's relation to another that lead him to see it as wolfish, that is, to take up the perspective of wolfishness on this relation. And it is natural to assume that these initiating beliefs are part of what he means to communicate. Without these beliefs there is no way to account for metaphoric thinking or the process of composition. And the audience, on the other hand, depends on these beliefs both for any framing-effect at all (without which we don't yet have a metaphor) and for the provisional interpretation of it. At this stage of the understanding of metaphor we look more to the speaker than to the world, for his false beliefs (for example, about the viciousness of wolves) will be as important to us as the actual facts about wolves.

Nonetheless, both the composer's elaboration of the metaphor in thought or speech, and the audience's interpretation of it, go beyond these initiating beliefs, even though both processes are dependent on them. The composer adopts the perspective he does partly because he expects that it will lead the mind in unanticipated directions. It is possible to get more out of it than one has explicitly put into it. And the audience as well may engage in interpretation of the metaphor that is an exploratory elaboration of it, and which involves attention to the world rather than to the speaker. It is a portion of the world, after all, that we have taken a certain perspective on; and at this further stage of interpretation we may leave the speaker behind, as he himself may leave behind his initiating beliefs and his own provisional understanding of the metaphor. We have taken up the particular framework or perspective, and now we pursue what can be noticed from it. ${ }^{26}$ This is the less communicative dimension of metaphor, the one which Davidson concentrates on and which involves adoption of a perspective rather than acceptance of an assertion. It is the less communicative aspect, since it is independent of the utterance's role in making an assertion (as opposed to, say, a question or the negation of the assertion). This, however, doesn't mean that it is a noncognitive dimension, for not only are the initiating beliefs part of the structure and content of this framing-effect, but the effect itself prompts and guides the elaboration of the metaphor in thought. This effect is what dies in the death of the metaphor, when it loses its vividness and suggestiveness, while it survives the denial or quotation of the metaphoric statement.

26. One hazard of discussing literary metaphors outside the context of the texts in which they operate is that it draws attention away from the otherwise obvious fact that the choice and development of a particular metaphor is also answerable to the whole metaphoric system of the text, both intra- and intertextual. 
Whereas, on the other hand, it is something of the other aspect-the initiating beliefs linking, say, bottle openings and mouths-that survives the death of the metaphor and that is denied in the denial.

A good metaphor does not just sum up the beliefs that led to it; it is meant to amplify and focus them, bringing them into contact with others. There will often be no sharp line between the earlier ideas that motivated a particular metaphor and the later ones that it, in turn, motivates. This raises the question of the relation between these two dimensions of metaphor: between the adoption of the perspective, on the one hand, and the thoughts that led to it and that it leads to, on the other. Such thoughts do not justify the adoption of the perspective; or, at least, the relation is not like that of various particular beliefs to a general one that is inferred from them. We may say that the initiating thoughts suggest the perspective, but that's not very helpful. We saw that we must consider the composer of the metaphor as first having some ideas about, for example, people's relations to strangers. What is it that motivates doing anything with these beliefs at this point, beyond just retaining them? And what is it that taking up the perspective of wolfishness is supposed to accomplish with regard to these thoughts? It may be said that the perspective organizes them; but a metaphor is not simply a mnemonic device, and in any case we still have to account for the further thoughts that are prompted by the perspective. There is, then, a question about what motivates going from one's initiating thoughts about the object to the adoption of a metaphoric perspective on it, and a question about how the perspective is related to the further thoughts it leads to. And these two questions must, I think, be answered together. For surely part of the reason the composer of the metaphor adopts a particular perspective is that he or she expects and wants it to lead him or her to notice something new, to thoughts that are relevant to the object.

If we could say more about the relation of the perspective to the new thoughts it prompts, beyond just saying that it prompts them, then we could say more about what motivates going from one's original beliefs to the adoption of any perspective in the first place. For, outside the use of metaphors as models in scientific theoryconstruction, the explication or following up of a metaphor is not the framing of a hypothesis. And its suggestiveness and the aptness of the ideas it leads to are not taken to be explanatory of, say, the nature of anyone's relation to strangers (as if we were descended from wolves, and so partook of their essence). No doubt many explanatory theories, good and bad, begin life as metaphors. But this is not what the ordinary engagement with or contemplation of a living metaphor is like. On the other hand, neither is it like finding the shape of a camel or a whale in the clouds in the sky. We do adopt a different perspective on 
the object, and regard it differently, and don't simply rebound associatively from it.

As the discussion of praeteritio suggested, it is easier to say how the picturing-dimension of metaphor may operate, and what it may gain for the speaker, in the context of speech acts, rhetoric, and dealing with others. It is harder to give an account of the cognitive function of the framing-effect in the context of the composition of the metaphor in thought. For this we would need a better understanding of such things as the figures one may find both uncashable and inescapable in one's thinking, and the situations of provisionally writing beyond oneself, or beyond one's present understanding of what one has written. For the turn to metaphor is not just slippage; it is also a calculated and conditional surrender to a quite particular verbal constellation.

\section{Figures and Pictures}

The story of metaphor's association with imagery and force is a tangled one, and further clarity here awaits a better understanding both of how pictures themselves signify and of how imagination tells us anything about the world. In the case of metaphor, some of the tangle is undone when we disambiguate phrases describing it as the "visibility of discourse." This could mean what Ted Cohen means when he speaks of metaphor as an utterance that draws attention to itself and its form, and throws into relief features of communication that are normally invisible because taken for granted. ${ }^{27}$ Or the phrase may be understood as Dan Sperber understands it: the figurative utterance is represented in quotes prior to interpretation and is thus a relatively opaque use of language reflecting attention back on itself. Either understanding of "visibility" is compatible with a denial of any special role for images as such in the functioning of metaphor. And neither of them should be confused with the idea of metaphor as the trope of resemblance. For even if resemblance required images, it is a relation between the things compared, and not a relation between the discourse and something else. If there is an iconic dimension to metaphor, it is not on the level of the linguistic sign itself. Metaphor is not onomatopoeia or part of a Cratylism of language. But while it doesn't itself resemble anything of the right kind, the metaphoric utterance creates a motivated sign out of something else. It makes the wolf symbolize someone's treatment of strangers; it is the wolf, and not the

27. Cohen, "Metaphor and the Cultivation of Intimacy," p. 6. 
form of the discourse, which stands in a figurative relation to what it represents.

The particular features of such a symbol that are relevant to its representation of its object are not specifiable in advance, and are not discoverable by reference to any code or formula. We know that not every fact about wolves is part of the comparison, yet we also know that we don't know in advance every fact that is part of it. This distinguishes metaphor from the formal analogies in geometry or music theory, which both systematically restrict the relevant dimensions of resemblance and provide rules for going from one element to another. The relationship between the wolf and what it symbolizes is not so defined. And because it is not, we cannot specify just which features are essential to it and must be shared by any replacement expression, nor which features of the symbol are indifferent to its symbolizing function (as are, for example, the color and width of the chalk lines of the figures in a geometry problem). ${ }^{28}$ This is a source of what is sometimes called the problem of paraphrase, the impossibility of finding a straight prose equivalent for a poetic metaphor. For a fully meant poetic metaphor, we have to take seriously the fact that it is not determined in advance just which features of it are signifying ones and which are not, for the function of a code, which is lacking here, is just to tell us what features to ignore. The active contemplation of a picture shares this characteristic, which may provide us with another reason why the metaphoric relationship is thought of as figurative.

However that turns out, the rhetorically significant relation between metaphor and images lies in the problematic relation they each have to assertion. Metaphor needn't provide us with an image, but it has an aspect-its framing-effect - that functions cognitively in a manner which is importantly similar to that of an image. (Though, as mentioned earlier, even this aspect is a structured comparison, unlike an image per se.) Calling a metaphor a figure is thus a figurative way of capturing this resemblance in functioning, and $I$ have tried explicating this figure here. Neither an image nor the framing-effect of a metaphor is itself an assertion, and neither is by itself a proper object of belief or denial. But whole networks of beliefs are both involved in their composition and are part of what their audiences recognize and are expected to take away with them. And although this process takes place largely outside the language-game of assertion, agreement, and denial, it is for all that a process of language and communication. Hence it remains a problem for a theory of language, whether or not the theory ends up providing metaphors with "meanings."

28. Here I am alluding to Goodman's characterization of what is special about pictures as consisting in their being part of a symbol system that is "syntactically and semantically dense." See his Languages of Art, pp. 225-41, esp. p. 234. 